\title{
Nucleotide excision repair and recombination are engaged in repair of trans-4-hydroxy-2-nonenal adducts to DNA bases in Escherichia coli
}

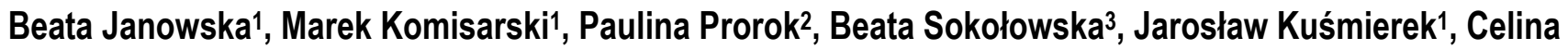 \\ Janion1, Barbara Tudek ${ }^{1,2} \bowtie$
}

1. Institute of Biochemistry and Biophysics, Polish Academy of Sciences, Pawińskiego 5a, 02-106 Warsaw, Poland;

2. Institute of Genetics and Biotechnology, Warsaw University, Pawińskiego 5a, 02-106 Warsaw, Poland;

3. Medical Research Center, Polish Academy of Sciences, Pawinskiego 5, 02-106 Warsaw, Poland

Correspondence to: Barbara Tudek, Institute of Biochemistry and Biophysics, Polish Academy of Sciences, Pawińskiego 5a, 02-106 Warsaw, Poland. Tel: (+4822) 592-3334; fax: (+4822) 592-2190; e-mail: tudek@ibb.waw.pl

Received: 2009.06.04; Accepted: 2009.09.15; Published: 2009.09.23

\begin{abstract}
One of the major products of lipid peroxidation is trans-4-hydroxy-2-nonenal (HNE). HNE forms highly mutagenic and genotoxic adducts to all DNA bases. Using MI 3 phage lacZ system, we studied the mutagenesis and repair of HNE treated phage DNA in E. coli wild-type or uvrA, recA, and mutL mutants. These studies revealed that: (i) nucleotide excision and recombination, but not mismatch repair, are engaged in repair of HNE adducts when present in phage DNA replicating in E. coli strains; (ii) in the single uvrA mutant, phage survival was drastically decreased while mutation frequency increased, and recombination events constituted $48 \%$ of all mutations; (iii) in the single recA mutant, the survival and mutation frequency of HNE-modified MI3 phage was slightly elevated in comparison to that in the wild-type bacteria. The majority of mutations in recA- strain were $\mathrm{G}: \mathrm{C} \rightarrow \mathrm{T}: \mathrm{A}$ transversions, occurring within the sequence which in $r e c A^{+}$strains underwent RecA-mediated recombination, and the entire sequence was deleted; (iv) in the double uvrA recA mutant, phage survival was the same as in the wild-type although the mutation frequency was higher than in the wild-type and recA single mutant, but lower than in the single uvrA mutant. The majority of mutations found in the latter strain were base substitutions, with G:C $\rightarrow$ A:T transitions prevailing. These transitions could have resulted from high reactivity of HNE with G and C, and induction of SOS-independent mutations.
\end{abstract}

Key words: trans-4-hydroxy-2-nonenal, HNE-DNA adducts, mutations, recombination, NER, M13 phage

\section{Introduction}

The oxidation of polyunsaturated fatty acids is a free radical process initiated by reactive oxygen species such as the hydroxyl radical. Lipid peroxidation leads to the formation of a large family of alkenals, but the major product of the peroxidation of $\omega-6$ polyunsaturated fatty acids is trans-4-hydroxy-2-nonenal (HNE) [1-5].

HNE occurs in tissues in the range of $0.1-3.0$ $\mu \mathrm{M}$, but under conditions of oxidative stress can in-

crease up to $50 \mu \mathrm{M}$ [4]. It is an important factor regulating cell metabolism as well as a contributor to several pathological processes. HNE is highly cytotoxic and induces apoptosis in neuronal cells. Neuronal apoptosis may occur in stroke [6-8] and in Alzheimer and Huntington diseases $[9,10]$. Antioxidants that suppress lipid peroxidation protect against apoptosis induced by oxidative insult, but not that induced by HNE. Glutathione binds HNE and protects neurons 
against apoptosis induced by oxidative stress and HNE [4]. PC12 cells expressing Bcl2 exhibit elevated levels of glutathione and lowered levels of HNE under oxidative stress [11]. Livers of humans with Wilson's disease and hemochromatosis contain mutations at $\mathrm{CpG}$ sites in the coding regions of the p53 tumor suppressor gene. It has been suggested that these mutations may be caused by modification of deoxyguanosine with HNE [3]. Genotoxic effects of HNE were also observed as a consequence of normal cellular metabolism. It was shown that choline-deficient L-amino acid defined diet (CDAA) caused hepatocellular carcinoma (HCC) in rats [12]. Mitochondria isolated from livers of rats fed the CDAA diet produced significantly more $\mathrm{H}_{2} \mathrm{O}_{2}$ per NADH reducing equivalents oxidized and contained significantly higher 8-oxodG level in DNA than rats fed a normal diet [13]. In pre-neoplastic liver foci of rats fed the CDAA diet adducts to DNA of the HNE analog, 4-oxo-2-nonenal (ONE), were detected after only three days on this diet [14]. This suggests that the CDAA diet induces oxidative stress associated lipid peroxidation and causes modifications of DNA bases in the early phase of carcinogenesis. It was also shown that a deficiency of glucose 6-phosphate dehydrogenase (G6PD) in the mouse mutant may cause endogenous oxidative stress, which generates trans-4-hydroxy-2-nonenal and causes tissue mutagenesis [15]. The brains of G6PD-deficient males exhibit a considerable accumulation of promutagenic etheno-DNA adducts (13-fold increase in etheno-deoxyadenosine and 5-fold increase in etheno-deoxycytidine), and substantial elevation of somatic mutation rates (3-fold increase in lacZ mutant frequencies, predominated by illegitimate genetic recombinations of lac $Z$ with mouse genomic sequences) [15].

So far, two types of mutagenic lesions arising by fatty acid oxidation have been described, bulky adducts to DNA bases, e.g., HNE-DNA adducts [16, 17], and relatively small etheno-adducts to $G, A$ and $C[3$, 18]. HNE forms adducts to all four DNA bases, namely, cyclic propano- or etheno-adducts bearing a hexyl- or heptyl- side chain [17]. In the presence of atmospheric oxygen or lipooxygenase, HNE can be transformed into 2,3-epoxy-4-hydroxynonanal (EH), and this compound modifies guanine, adenine and possibly other DNA bases in nucleosides and nucleic acids much more efficiently than HNE [3]. The aldehyde group of propano-type HNE adduct to guanine, and most probably to the other DNA bases, is labile and in dsDNA may react with amino groups of nucleic acid bases and/or proteins, forming DNA-DNA and DNA-protein crosslinks [19].
In the model studies HNE is mutagenic, and induces a dose-dependent SOS response in S. typhimurium [20], HPRT mutations in V79, and sister chromatid exchanges in Chinese hamster ovary and in cultured mammalian cells [21,22].

HNE-dG adducts in DNA were shown to be recognized by bacterial and mammalian nucleotide excision repair (NER) system [23]. However, the consequences of NER deficiency in bacteria and in mammalian cells have not been described extensively. The present paper attempts to remedy this situation.

\section{Materials and Methods}

\section{I.Oligonucleotides and substrates}

HNE was synthesized in the form of dimethylacetal derivative according to Chandra and Srivastava [24]. Prior to use, the dimethylacetal of HNE was hydrolyzed to aldehyde by incubation in $0.01 \mathrm{M} \mathrm{HCl}$ in a methanol-water $2: 1$ solution at $37^{\circ} \mathrm{C}$ for $1 \mathrm{~h}$ and neutralized with $1.5 \mathrm{M}$ triethylammonium bicarbonate (TEAB) buffer $\mathrm{pH}$ 5.5. The BT3 primer used in this study for sequencing of the lac $Z \alpha$ gene, 5'-TCG CCA TTC AGG CTG CG-3', was synthesized according to standard procedures using an Applied Biosystems synthesizer (Oligonucleotide Synthesis Laboratory, IBB PAS, Warsaw, Poland). The T7 Sequencing Kit (version 2 ) and $[\alpha-355]-d A T P$ were from Amersham-Pharmacia Biotech. (Uppsala, Sweden) or ICN (PerkinElmer Life Sci., Boston, MA, USA). dNTPs were from Sigma (St. Louis, MI, USA), X-gal from $\mathrm{POCH}$ (Gliwice, Poland) and IPTG from Promega (Madison, WI, USA).

\subsection{Bacteria, phages and media}

Characteristics of bacterial strains are given in Table 1. Media and plates used for bacterial growth and M13 transfectants were as described before [25].

Table I. Bacterial E. coli KI2 strains used in this study.

\begin{tabular}{|c|c|c|c|}
\hline Strain & Genotype & Phenotype & $\begin{array}{l}\text { Source or } \\
\text { reference }\end{array}$ \\
\hline JM105 & $\begin{array}{l}\text { E.coli K12 (supE endA sbc } \\
\text { B15 hsd R4 rpsL thi } \\
\text { A(lac-proAB)/F'lacZ } \\
\text { AM15) }\end{array}$ & $\begin{array}{l}\text { wild-type for } \\
\text { DNA repair }\end{array}$ & $\begin{array}{l}\text { IBB PAS } \\
\text { collection }\end{array}$ \\
\hline BH1100 & as JM105 but $r e c A:: \mathrm{Cm}^{\mathrm{r}}$ & $\begin{array}{l}\text { Recombination } \\
\text { and SOS deficient }\end{array}$ & $\begin{array}{l}\text { R. Devoret } \\
\text { collection }\end{array}$ \\
\hline BH430 & as JM105 but $u v r A::$ Tet $^{r}$ & NER deficient & $\begin{array}{l}\text { S. Boiteux } \\
\text { collection }\end{array}$ \\
\hline BJ1 & as $\mathrm{BH} 430$ but $r e c A:: \mathrm{Cm}^{\mathrm{r}}$ & $\begin{array}{l}\text { NER, recombina- } \\
\text { tion and SOS defi- } \\
\text { cient }\end{array}$ & $\begin{array}{l}\text { IBB PAS } \\
\text { collection }\end{array}$ \\
\hline BJ2 & as JM105 but mutL::Kan ${ }^{\mathrm{r}}$ & MMR deficient & $\begin{array}{l}{[\mathrm{Pl}(\mathrm{NR} 9559)} \\
\rightarrow \mathrm{JM}^{\mathrm{N}} 105 \\
\left.\mathrm{Kan}^{\mathrm{r}}\right][45] \\
\text { This work }\end{array}$ \\
\hline $\mathrm{BJ} 3$ & as $\mathrm{BH} 430$ but $m u t L:: \mathrm{Kan}^{\mathrm{r}}$ & $\begin{array}{l}\text { NER, MMR defi- } \\
\text { cient }\end{array}$ & $\begin{array}{l}{[\mathrm{Pl}(\mathrm{NR} 9559)} \\
\rightarrow \mathrm{BH}^{2} 30 \\
\left.\mathrm{Kan}^{\mathrm{r}}\right][45] \\
\text { This work }\end{array}$ \\
\hline
\end{tabular}


To construct new strains bacteria were routinely transformed with the P1vir phage [26].

M13 mp18 contains an operator, promoter and fragments of the $\mathrm{N}$-terminal part of lac $Z$ sequences (lac $Z \alpha$ ) encoding $\beta$-galactosidase. Its $\mathrm{C}$-terminal part (with operator and promoter) encoding the 146 amino acid part of the lacZ gene (lacZ $\beta$ ) is situated on the $\mathrm{F}^{\prime}$ episome of the derivatives of JM105 bacterial host strain. These fragments restore $\beta$-galactosidase activity by $\alpha$-complementation; hence, by sequencing the M13mp18 phage we can detect the forward mutations in the lac $Z \alpha$ fragment caused by point or frameshift mutations or by RecA-mediated recombination.

\subsection{Modification of phage DNA}

M13mp18 phage was grown overnight at $37^{\circ} \mathrm{C}$ in E. coli strain JM 105 (Table 1) in 2YT medium. The phage was collected and its DNA isolated according to Messing [27]. Double stranded M13 phage DNA was incubated with 20,50 and $100 \mathrm{mM}$ HNE at pH 5.5 for $48 \mathrm{~h}$, at $37^{\circ} \mathrm{C}$. Control, untreated, phage DNA was prepared in the same way, but HNE was substituted with water. For each HNE concentration, as well as for control DNA, $20 \mu \mathrm{g}$ of phage DNA in a total volume of $100 \mu \mathrm{l}$ was used. Subsequently, the DNA was precipitated with ethanol and resuspended in $100 \mu \mathrm{l}$ of sterile water.

\subsection{Preparation of competent cells and trans- formation}

Bacteria were made competent by the $\mathrm{CaCl}_{2}$ method [28]. Transfection was performed according to Sambrook et al. [28]. Phage DNA (100 ng) was used to transfect $100 \mu \mathrm{l}$ of competent cells. Transfection mixtures were plated on LB solid medium with $3 \mathrm{ml}$ of LB soft agar supplemented with $0.4 \mathrm{mM}$ IPTG and $0.5 \mathrm{mg} / \mathrm{ml} \mathrm{X-gal}$. Plates were incubated overnight at $37^{\circ} \mathrm{C}$ and plaques of phage infection centers were scored.

\subsection{Collecting lacZ $\alpha$ mutants and their se- quencing}

M13 lacZ $\alpha$ mutants lacking $\alpha$-complementation and exhibiting low or no $\beta$-galactosidase activity were recognized as colorless or light blue plaques on LB plates containing IPTG and X-gal. For each bacterial strain used, from 10000 to 30000 plaques were analyzed, and 30 - 70 individual mutant phages were isolated only from plates with $100 \mathrm{mM}$ HNE. The frequency of mutations was determined by the ratio of colorless or light blue plaques to all plaques formed after transfection of phage DNA modified with a defined HNE concentration. DNA of mutated phages was isolated and sequenced using the dideoxynu- cleotide chain termination method [28, 29]. The T7 Sequencing Kit, $\left[\alpha^{35} S\right]$-dATP and a specific 19 nucleotide primer (BT3) annealing at base positions for amino acids 71-78 of the lacZ gene of the M13 "+" strand were used for DNA sequencing. To ensure that mutants were not derived from expansion of clones, eight independent HNE modifications of the phage DNA were performed. Only one transformation was done after each DNA modification, and transfection mixtures were plated onto 4 plates. Usually only one mutant was picked up from each plate (three at maximum).

\subsection{Statistical Analysis}

All data are presented as means \pm SD. The STATISTICA (version 5.1) computer software (Stat Soft, Inc., Tulsa) was used for the statistical analysis. All parameters were tested for normal distribution with the tests of Shapiro-Wilk and Kolmogorov-Smirnov with Lillefors correction. The homogeneity of variances was evaluated by the Leven test. Differences among strains were evaluated using ANOVA. Statistical significance was considered at $P<$ 0.05 .

\section{Results}

\section{I. Effect of host bacteria on survival and lacZ $\alpha$ mutations induced by HNE-treatment of dsDNA of MI 3 phages}

Modification of double stranded M13 phage DNA with HNE resulted in a decrease in phage survival and increase in mutation frequency of the lacZ $\alpha$ gene of the M13 phage. As host bacterial strains for phage development we used: JM105 wild-type in DNA repair; $\mathrm{BH} 430$ (uvrA), lacking nucleotide excision repair (NER); BH1100 (recA), lacking RecA-recombinational and $\operatorname{Rec} A^{*}$ coprotease activities; and BJ1 (uvrA recA), lacking both RecA-recombinational and NER mediated repair.

Growth and mutagenesis of HNE-treated M13 mp18 phage differed in different bacterial hosts (Figs. 1,2 ; Tables 2, 3). The lowest survival and the highest mutation frequency in the lacZ $\alpha$ gene of M13 phage were observed in the BH430 strain deficient in the NER system (Fig. 1). Mutation frequency increased 10 -fold, at survival rate of $8.3 \%$ when phage DNA was modified with $100 \mathrm{mM}$ HNE. In comparison, in the wild-type E. coli JM105 strain, after the same modification of phage DNA, the mutation frequency increased 3.2 -fold, at survival rate of $27.5 \%$. The differences in mutation frequency and survival between the wild-type and NER-deficient strains were statistically significant $(P=0.0002)$. These results confirm the participation of NER in repair of HNE-DNA adducts in 
bacteria and mammals, as suggested by Feng et al. and $\mathrm{Hu}$ et al. $[16,23]$. The predominant increase in mutations in $u v r A$-defective BH430 host-strain was due to recombinantional events, formed by simultaneous deletions of 93- ( $\Delta \mathrm{M} 15$ of $\mathrm{F}^{\prime}$ lacZ) and 54- nucleotides of polylinker fragments, as described in the legend to Fig.3. They constituted $48 \%$ of all mutants, while in the wild-type and $\mathrm{rec}^{-}$strain only $10 \%$ of recombination events were found, and no recombinational repair was found in the double JM105 recA-uvrA- strain (Table 2). Our previous studies on the mutagenic activity of HNE-treated M13mp18 ssDNA showed that HNE treatment inhibits replication and stimulates phage recombination with homologous lac $Z$ gene sequences localized in the $\mathrm{F}^{\prime}$ factor in bacteria [17]. Here we observed that the deficiency of functional RecA protein did not decrease phage survival. In contrast, better survival $(P=0.002$ at $100 \mathrm{mM} \mathrm{HNE})$, and increased lacZ $\alpha$ mutation rate $(P=0.03$ at $100 \mathrm{mM} \mathrm{HNE})$ of HNE-modified M13 phage was observed in recA- E. coli in comparison to the wild-type bacteria (Tables 2 and 3 and Fig. 1).

Table 2. Types and frequency $\left(\times 10^{-5}\right)$ of lacZa mutations induced by HNE treatment of dsDNA of MI3mpl8 phage and allowing it to replicate in E. coli wild-type and mutants defective in NER and/or recA-dependent recombination.

\begin{tabular}{|c|c|c|c|c|c|c|c|c|c|c|}
\hline \multirow{3}{*}{ Type of mutation } & \multirow{2}{*}{\multicolumn{2}{|c|}{$\begin{array}{l}\text { Spontaneous muta- } \\
\text { tions } \\
\text { JM105 (wild-type) }\end{array}$}} & \multicolumn{8}{|c|}{ HNE-induced mutations } \\
\hline & & & \multicolumn{2}{|c|}{ JM105 (wild-type) } & \multicolumn{2}{|l|}{ BH1100 (recA) } & \multicolumn{2}{|l|}{ BH430 (uvrA) } & \multicolumn{2}{|l|}{ BJ1 (uvrArecA) } \\
\hline & $\begin{array}{l}\text { mutation fre- } \\
\text { quency } \\
\text { x10-5 }\end{array}$ & $\%$ & $\begin{array}{l}\text { mutation fre- } \\
\text { quency } \\
\text { x10-5 }\end{array}$ & $\%$ & $\begin{array}{l}\text { mutation fre- } \\
\text { quency } \\
\text { x10-5 }\end{array}$ & $\%$ & $\begin{array}{l}\text { Mutation fre- } \\
\text { quency } \\
\text { x10-5 }\end{array}$ & $\%$ & $\begin{array}{l}\text { mutation fre- } \\
\text { quency } \\
\text { x10-5 }\end{array}$ & $\%$ \\
\hline Base substitutions & 33.3 & 61.3 & 108 & 80 & 164.6 & 84.2 & 217.2 & 48 & 288 & 94.7 \\
\hline \multicolumn{11}{|l|}{ Frameshifts } \\
\hline - insertions & $\mathrm{nd}^{*}$ & \multirow[t]{2}{*}{9.7} & 6.75 & \multirow[t]{2}{*}{10} & nd & \multirow[t]{2}{*}{5.3} & 18.8 & \multirow[t]{2}{*}{4} & 16 & \multirow[t]{2}{*}{5.3} \\
\hline - deletions & 6 & & 6.75 & & 10.3 & & nd & & nd & \\
\hline $\begin{array}{l}\text { Recombination deletion } \\
\text { of } 93+54 \text { nucleotides }\end{array}$ & 3.5 & 6.5 & 13.5 & 10 & 20.6 & 10.5 & 217.2 & 48 & nd & nd \\
\hline Other deletions & 12 & 22.5 & nd & nd & nd & nd & nd & nd & nd & nd \\
\hline Total & 54.8 & 100 & 135 & 100 & 195.5 & 100 & 453.2 & 100 & 304 & 100 \\
\hline
\end{tabular}

*nd - not detected

Table 3. Types and frequency $\left(\times 10^{-5}\right)$ of lacZa base substitutions mutations induced by HNE treatment of dsDNA of MI3mpl 8 phage and allowing it to replicate in E. coli wild-type and mutants defective in NER and/or recA-dependent recombination.

\begin{tabular}{|c|c|c|c|c|c|}
\hline \multirow[b]{2}{*}{ Type of mutation } & \multirow{2}{*}{$\begin{array}{l}\text { Spontaneous muta- } \\
\text { tions } \\
\text { JM105 (wild-type) }\end{array}$} & \multicolumn{4}{|c|}{ HNE-induced mutations } \\
\hline & & JM105 (wild-type) & BH1100 (recA) & BH430 (uvrA) & BJ1 (uvrArecA) \\
\hline $\mathrm{A}: \mathrm{T} \rightarrow \mathrm{G}: \mathrm{C}$ & 3.5 & 6.75 & $\mathrm{nd}^{*}$ & 18.1 & 16 \\
\hline $\mathrm{A}: \mathrm{T} \rightarrow \mathrm{C}: \mathrm{G}$ & 2 & 6.75 & nd & nd & nd \\
\hline $\mathrm{A}: \mathrm{T} \rightarrow \mathrm{T}: \mathrm{A}$ & 2 & nd & nd & 18.1 & nd \\
\hline $\mathrm{G}: \mathrm{C} \rightarrow \mathrm{T}: \mathrm{A}$ & 5 & 20.25 & 82.3 & 36.2 & 32 \\
\hline $\mathrm{G}: \mathrm{C} \rightarrow \mathrm{C}: \mathrm{G}$ & 5 & nd & nd & 18.1 & 16 \\
\hline $\mathrm{G}: \mathrm{C} \rightarrow \mathrm{A}: \mathrm{T}$ & 15.8 & 74.25 & 82.3 & 126.7 & 224 \\
\hline Total & 33.3 & 108 & 164.6 & 217.2 & 288 \\
\hline
\end{tabular}

*nd - not detected 

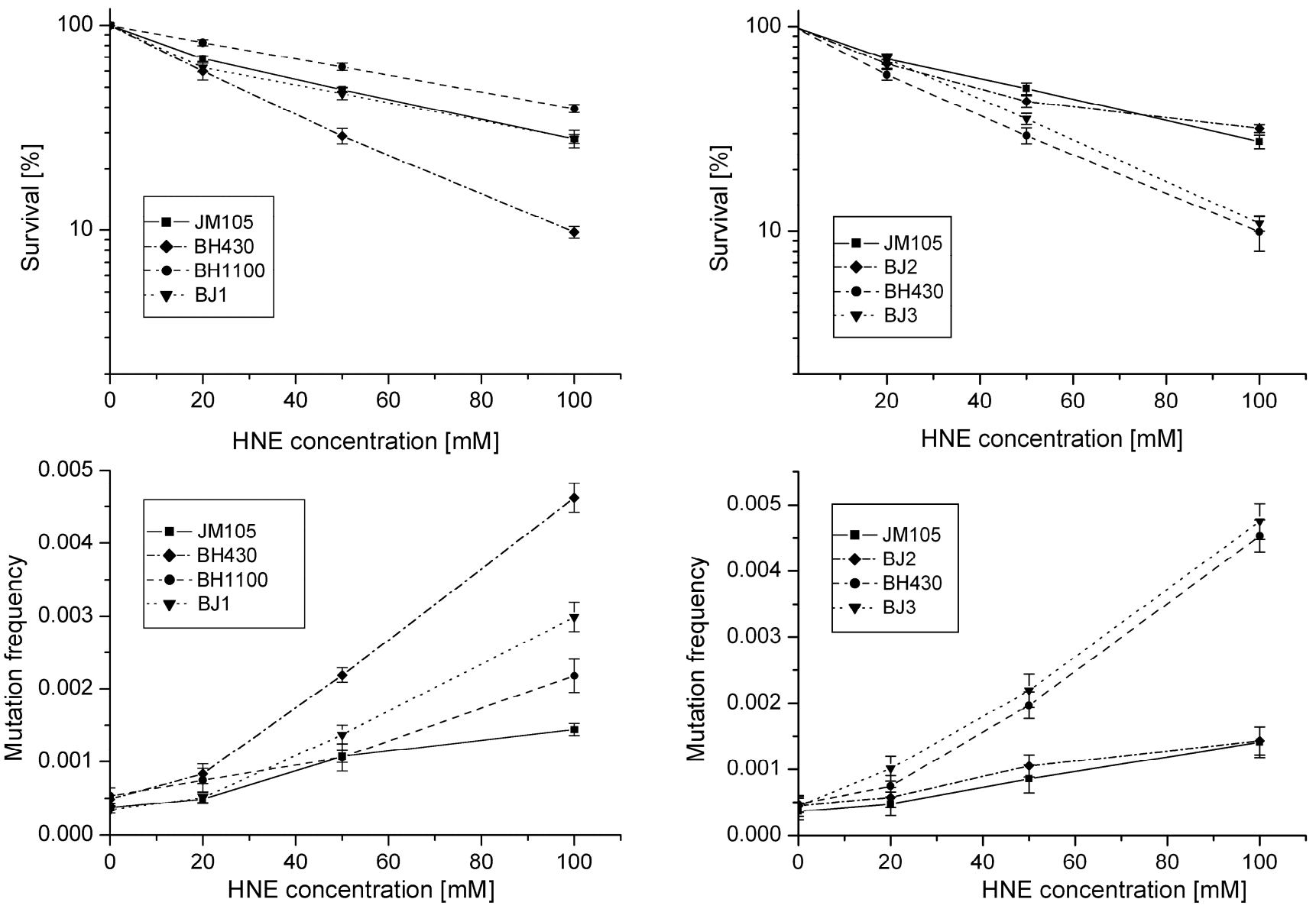

Fig. I. Survival and mutation frequency in the lac $Z$ gene of MI3mpl 8 phage DNA modified with HNE and transfected into wild-type $E$. coli and its uvrA and recA mutants.

In the double $u v r A-r e c A$ - defective strain the efficiency of infective centers formation by HNE-modified phage DNA was the same as in the wild-type bacteria; however, the total mutation rate (including base substitutions, frameshifts and recombinations) was higher than in the wild-type strain $(P=0.0005$ at $100 \mathrm{mM} \mathrm{HNE})$, but still lower than in the uvrA- single mutant $(P=0.0003$ at $100 \mathrm{mM} \mathrm{HNE})$.

In order to obtain insight into the possible role of mismatch repair system in avoiding the deleterious effects of HNE-DNA adducts, we verified propagation and mutagenesis of HNE modified phage in the $m u t L^{-}$strain. No differences in survival or mutation rate were found between M13 phage transfected into E. coli wild-type or its $m u t L^{-}$derivative, or into E. coli uvrA- or uvrA- mutL- strains (Fig. 2).

\subsection{Spectrum of $\operatorname{lac} Z \alpha$ gene mutations induced by HNE-treatment of MI3mpI 8 dsDNA}

Mutants in lac $Z \alpha$ gene obtained after treatment of M13 phage DNA with $100 \mathrm{mM}$ HNE were sequenced, and the results of these analyses are summarized in Tables 2 and 3 and in Figs. 3-6. In HNE-treated M13 phage DNA propagated in wild-type JM105 strain, lacZ $\alpha$ mutants arose mainly by base substitutions (80 \%), in which $\mathrm{G}: \mathrm{C} \rightarrow \mathrm{A}: \mathrm{T}$ transitions prevailed (69\% of total base substitutions), with $10 \%$ due to frameshifts (-G deletions or $+\mathrm{T}$ insertions), and to $10 \%$ recombination events. G:C $\rightarrow$ A:T transitions were detected as $\mathrm{C} \rightarrow \mathrm{T}$ mutations, of which almost all were focused in two mutational hotspots (Fig. 4). The $\mathrm{C} \rightarrow \mathrm{T}$ transitions also prevailed in the spectrum of spontaneous mutations, but they were mapped at different loci of the lac $Z \alpha$ gene than the HNE-induced mutations, and their efficiency increased 5.4-fold. 


\section{JM105}

5' -GCGCAACGCAATTAATGTGAGTTAGCTCACTCATT

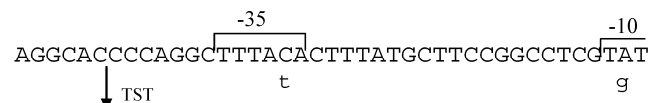

GTTGTGTGGAATTGTGAGCGGATAACAATTTCACACAGGAAACAGCT

1

ATG ACC ATG ATT ACG AAT TCG AGC TCG GTA CCC $\stackrel{-9}{9}$ GG GAT $\downarrow$

CCT CTA GAG TCG ACC TGC AGG CAT GCA AGC TTG GCA CTG

$$
\begin{aligned}
& \begin{array}{ccccccc}
2 & & \text { TT } & & & \\
\downarrow & & \text { TT } & & & \\
\text { C } & -a & T & C & T & A
\end{array} \\
& \begin{array}{cccccc}
\text { GCC GTC GTT TTA CAA CGT CGT GAC TGG GAA AAC CCT GGC } \\
+\mathrm{T} & - & -\mathrm{G} & \mathrm{C} &
\end{array} \\
& \mathrm{TT} \\
& \text { GTT ACC CAA CTT AAT CGC CTT GCA GCA CAT CCC CCT TTC } \\
& t g r t
\end{aligned}
$$

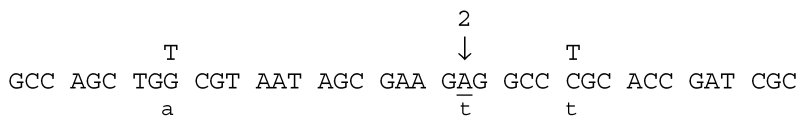

$$
\begin{aligned}
& \text { CCT TCC CAA CAG TTG CGC AGC CTG AAT GGC GAA TGG CGC } \\
& t \quad t \quad t \quad t \quad c \\
& \text { TTT GCC TGG TTT CCG GCA CCA GAA GCG GTG CCG GAA AGC } \\
& \text { TGG CTG GAG TGG GAT CTT CCT GAG GCC GAT ACT-3' }
\end{aligned}
$$

Fig. 3. Spectrum of HNE-induced point mutations in dsMI3mpI8 lacZ DNA transfected into the $E$. coli JMI05 strain. The 5' $\rightarrow$ ' DNA sequence of the lac $Z$ fragment of MI3mpl8 is shown, from the first nucleotide after lacl termination codon through the coding sequence for aminoacid 65 of the gene. The -10 and -35 promoters, as well as transcription start site (TST) are marked over the sequence. Base substitution mutations are marked in capital letters above the sequence, and frameshifts below, with indication of a subtraction ("-") or addition ("+") event. Spontaneous base substitutions are superimposed on the spectrum, and are marked below the sequence in a lower case, while spontaneous frameshift mutations are marked above the sequence, also in a lower case. (I) First and last nucleotide of the 54-nucleotide deletion of the polylinker region; (2) first and last nucleotide of the 93-nucleotide MI5 deletion.

Deficiency in DNA repair activity of bacterial hosts remarkably increased the rate of HNE-induced mutations, and completely changed their mutational spectrum.

While in HNE-treated M13 phages grown in JM105 wild-type strain G:C $\rightarrow$ A:T transitions were more abundant than $\mathrm{G}: \mathrm{C} \rightarrow \mathrm{T}: \mathrm{A}$ transversions, in phages grown in $\mathrm{BH} 1100 \mathrm{rec} A$ - deficient strain, the number of $\mathrm{G}: \mathrm{C} \rightarrow \mathrm{T}: \mathrm{A}$ and $\mathrm{G}: \mathrm{C} \rightarrow \mathrm{A}: \mathrm{T}$ mutations was equal (Table 3). Moreover, almost all (7 of 8) G:C $\rightarrow$ $\mathrm{T}: \mathrm{A}$ transversions detected as $\mathrm{G} \rightarrow \mathrm{T}$ mutations, when phages were grown in recA-defective strain, were mapped at codon AGC situated inside the 94 nucleotide $\Delta \mathrm{M} 15$ fragment, which in the recA-positive cells undergoes deletion by recombination (Fig.5).

Interestingly, in $u v r A^{-} r e c A^{-}$bacterial strain in which HNE-treated phage DNA survival was the same as in the wild-type strain, G:C $\rightarrow$ A:T substitutions still dominated ( $70 \%$ of all mutations), but no hotspot in $\mathrm{G} \rightarrow \mathrm{T}$ transversion was observed; moreover the total mutation frequency was decreased in comparison to uvrA single mutant (Table 3, and Figs. $1,4,5)$. A wider spectrum could be observed in $u v r A^{-}$ recA- bacterial host; additionally, the following mutations were found: $\mathrm{G}: \mathrm{C} \rightarrow \mathrm{T}: \mathrm{A}, \mathrm{G}: \mathrm{C} \rightarrow \mathrm{C}: \mathrm{G}, \mathrm{A}: \mathrm{T} \rightarrow \mathrm{G}: \mathrm{C}$, and frameshift $(+\mathrm{A})$.

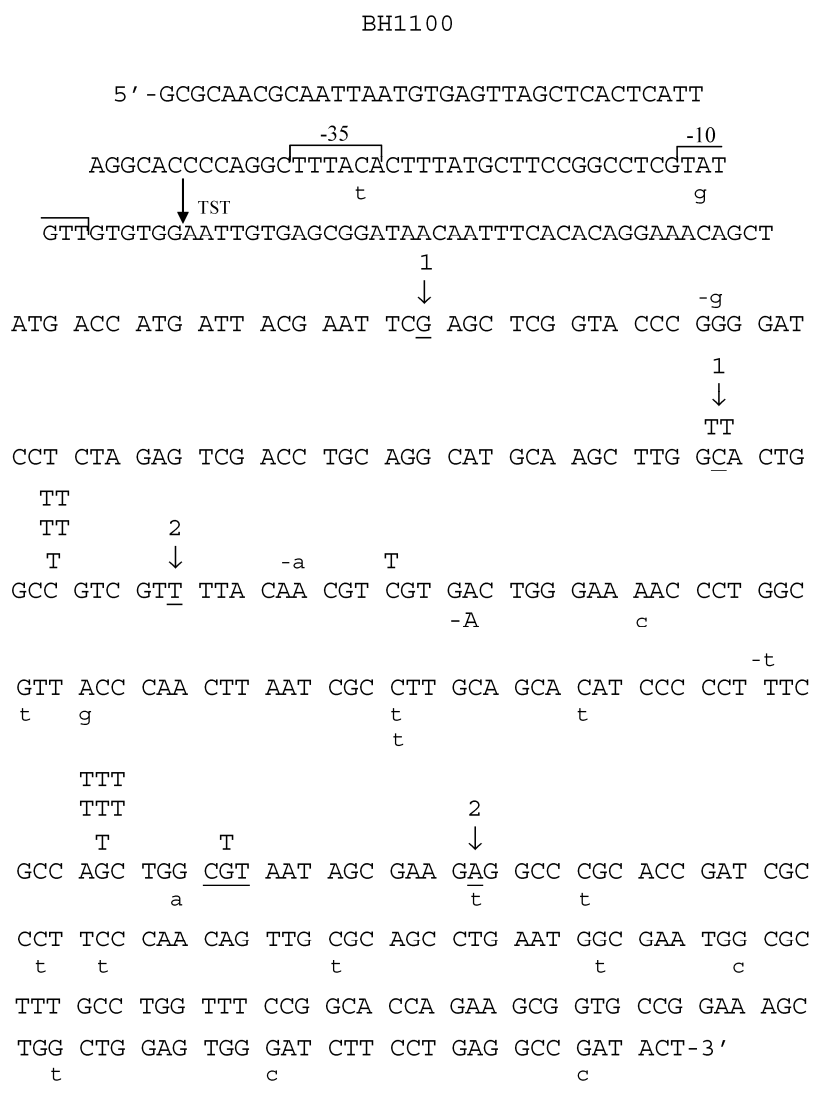

Fig. 4. Spectrum of HNE-induced point mutations in dsMI3mpI8 lacZ DNA transfected into the E.coli JMI05 recA strain. Explanations as in Fig. 3. Underlined triplet CGT is a hotspot for $\mathrm{G} \rightarrow \mathrm{T}$ transversions in HNE-modified ssDNA of MI3mpl8 phage [17]. 
BH4 30

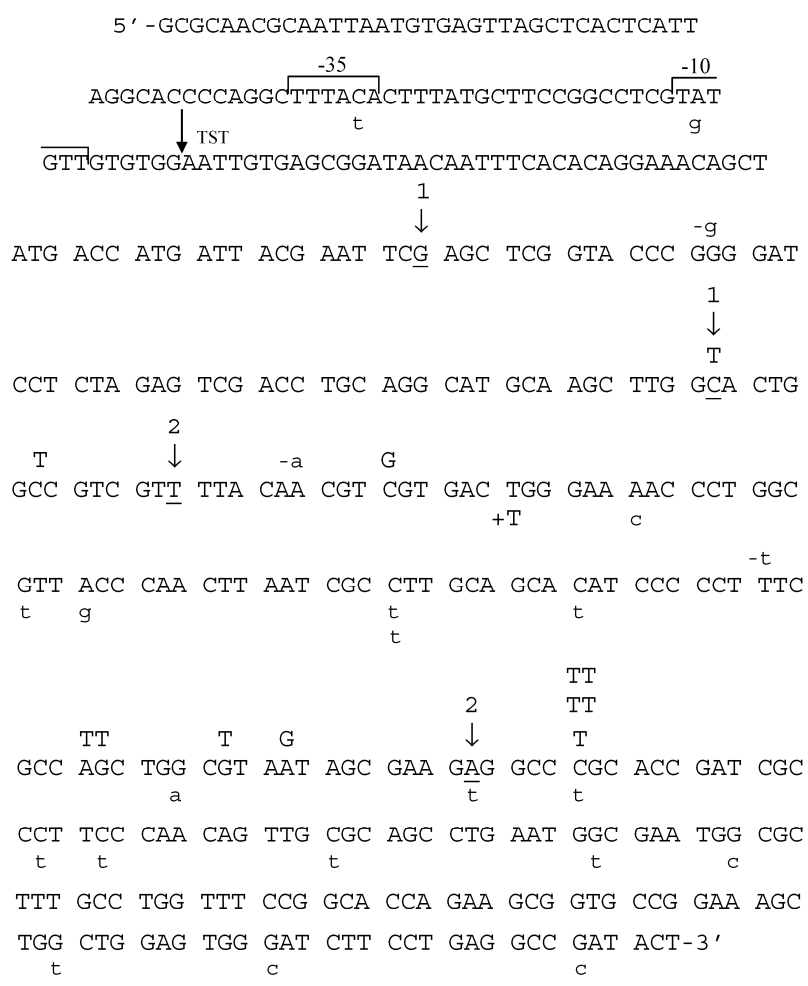

Fig. 5. Spectrum of HNE-induced point mutations in dsMI3mpI8 lacZ DNA transfected into the E. coli JMI05 uvrA strain. Explanations as in Fig. 3.

Fig. 6. Spectrum of HNE-induced point mutations in dsMI3mpI8 lacZ DNA transfected into the E. coli JMI05 recA'urrA strain. Explanations as in Fig. 3.

\section{Discussion}

It was previously shown that HNE, one of the major products of fatty acid peroxidation, and 2,3-epoxy-4-hydroxynonanal (EH) are strongly genotoxic for bacterial and mammalian cells [17, 30]. In vitro at $\mathrm{pH} 7.2$, HNE forms adducts to all four deoxynucleosides with the following reactivity: $\mathrm{dG} \geq \mathrm{dC}$ $>\mathrm{dA}>>\mathrm{dT}$ [17]. Upon an oxygen shock HNE may be further oxidized to EH, which reacts with DNA bases more readily than HNE to form mutagenic etheno-G, etheno- $\mathrm{C}$ and etheno- $\mathrm{A}$ derivatives with long alkyl side chains [2]. In our study we were unable to measure the level of HNE-DNA adducts in M13 DNA.
However, a brief estimation of adduct number can be proposed, based on literature data. On average, 1.2 HNE-dG adducts per 1000 bp were quantified in plasmid DNA modified in vitro with $192 \mathrm{mM} \mathrm{HNE}$ for $20 \mathrm{~h}$ [31]. Thus, at $100 \mathrm{mM}$ HNE approximately 0.6 HNE-dG adducts/1000 bp, which equals to 3.6 per 6 kb M13 phage DNA, may be expected in our study. The same number of HNE-dC adducts is probably formed since in free nucleosides the efficiency of HNE adduction to $\mathrm{dG}$ and $\mathrm{dC}$ is almost equal, while $\mathrm{A}$ and $\mathrm{T}$ are at least an order of magnitude less reactive [17].

Lipid peroxidation results also in the formation of mutagenic etheno-adducts to G, C and A without alkyl side chain [30]. These latter lesions are removed by base excision repair (BER) [32] and by AlkB oxidoreductase that is expressed in E. coli as a part of the Ada-system [33]. AlkB homologues exist also in human cells [34].

Many of the lesions in DNA (e.g., bulky adducts, like HNE-DNA adducts, cyclic pyrimidine dimers, pyrimidine-pyrimidone 6-4-photoproducts, 3meA, apurinic sites, and others) arrest DNA synthesis, and require induction of the SOS system to recover replication and induce mutations. In spite of the different types of DNA modifications, induction of the SOS response follows a similar scheme: (i) modified DNA

$\mathrm{BJ} 1$

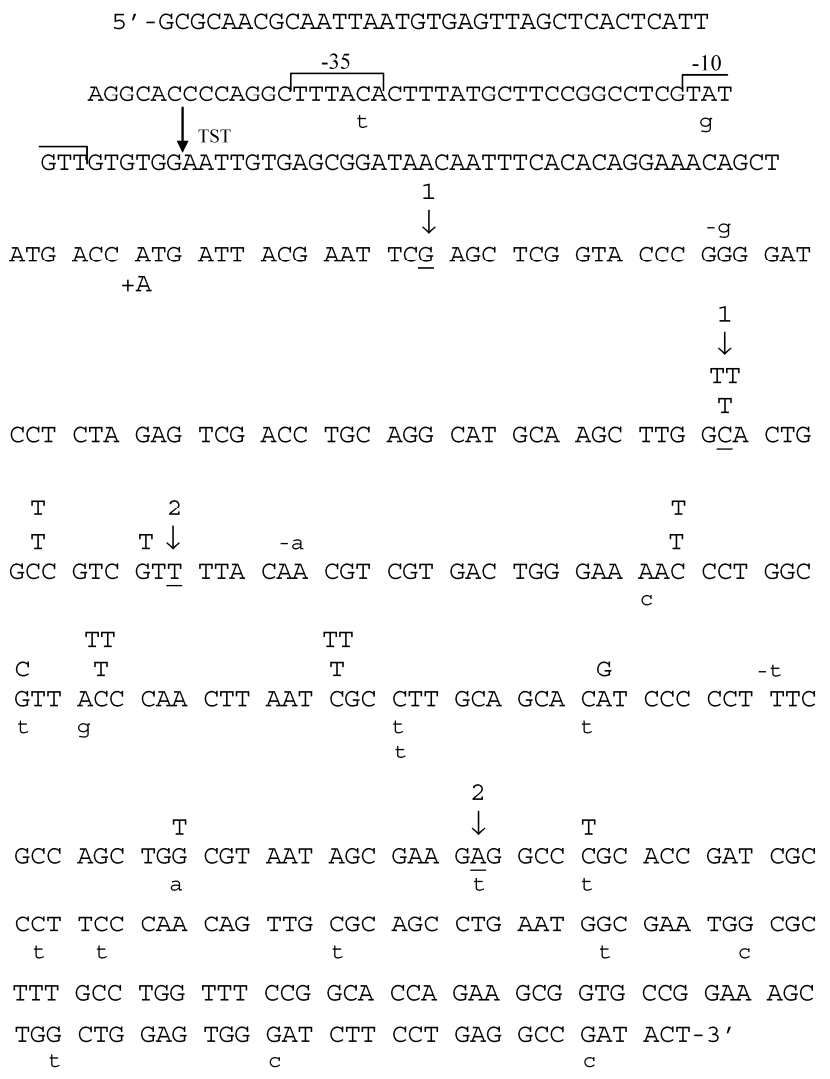


arrests DNA replication and induces formation of ss-DNA; (ii) RecA protein forms with ssDNA a ssDNA/RecA filament, which acquires Rec* coprotease activity that helps LexA protein (SOS suppressor) to undergo autocleavage and more than 50 SOS-regulated proteins to be expressed. Among them are mutagenic DNA polymerases, PolII, PolIV or PolV. All these DNA polymerases may incorporate nucleotides by translesion synthesis (TLS) past the damaged base and induce mutations. Selection of DNA polymerase in an error-prone process depends on the kind of lesion. PolV (UmuD' $\left.{ }_{2} \mathrm{C}\right)$ is the most error prone and the most frequently used [35]. Error-prone DNA polymerases and a similar mechanism of mutagenesis exist also in mammalian cells and constitute the DNA damage response [36].

HNE (at physiological concentrations) is a potent inducer of the SOS response [20]. Moreover, transfection of M13 DNA, in which replication of DNA is arrested, most probably induces the SOS response [37]. However, in this study we observed independence of HNE-induced base substitution mutations of RecA protein expression, since an increased level of mutations was found also in recA- bacterial hosts. Examples of this are hot-spotted HNE-induced G:C $\rightarrow$ T:A mutations which occur only in HNE-modified phages propagated in bacteria deficient in recA, as well as the high frequency of $\mathrm{G}: \mathrm{C} \rightarrow \mathrm{A}: \mathrm{T}$ transitions in $u v r A^{-}$rec $A^{-}$ double mutant.

In comparison to spontaneous mutation rate, HNE-treatment of M13 phage DNA increased G:C $\rightarrow$ A:T transitions frequency from 5.4-fold, when the phage was propagated in the wild-type JM105 strain, to 16-fold, when HNE-damaged phage was propagated in the uvr $A^{-}$rec $A^{-}$mutant. In rec $A^{-}$defective bacteria the frequency of HNE-induced G:C $\rightarrow$ A:T transitions was similar to that in the wild-type strain, while in the uvrA- strain the frequency of these mutations increased 9-fold in comparison to the rate of spontaneous mutations. This suggests that the HNE-cytosine adduct may have a strong miscoding potential, and mutations may arise in an SOS-independent manner. Since we used dsDNA of M13 phage for HNE modification and transformation, $\mathrm{C} \rightarrow \mathrm{T}$ mutations detected in the spectrum might derive from $\mathrm{HNE}$ adduction to $\mathrm{C}$ or to $\mathrm{G}$. However, comparison of HNE mutational spectra in dsDNA (Table 3) to those obtained previously for ssDNA of M13 phage [17] shows almost identical specificity of mutations; this strongly suggests that cytosine-HNE adduct(s) is a potent error-prone DNA lesion, inducing $\mathrm{C} \rightarrow \mathrm{T}$ transitions [38]. In addition, our previous study [17] as well as literature data suggest that the major mutation induced by HNE-dG adduct(s) is a G $\rightarrow \mathrm{T}$ transversion [38], and $\mathrm{G} \rightarrow \mathrm{A}$ transitions are formed to a much lesser extent.

The fact that the frequency of HNE-induced G:C $\rightarrow$ A:T mutations, detected as $\mathrm{C} \rightarrow \mathrm{T}$ transitions, increased twice in the $u v r A^{-}$strain and three times in the uvrA-rec $A^{-}$double mutant in comparison to that in the wild-type strain suggests that these adducts may be repaired either by NER or by recombination. In the absence of active RecA and NER proteins, HNE-dC adducts may probably be bypassed by replicative DNA polymerase more easily than other HNE DNA adducts in an error-prone mode. Our previous studies suggest that reaction of $\mathrm{HNE}$ with $\mathrm{dC}$ yields four different products, two containing cyclic rings and two linear ones [17]. In contrast, HNE-dG adducts remain mainly in the form of exocyclic rings in deoxynucleosides and ssDNA. Linear adducts are more flexible than exocyclic rings, and replicative DNA polymerase or DNA polymerase IV present in SOS-uninduced cells [35, 39] might more easily incorporate mismatched nucleotides opposite the lesion, and induce mutations. It is also possible that the bypass of HNE-dC or HNE-dG adducts by SOS DNA polymerases (pol II and pol IV) present in SOS uninduced cells is either error-prone or error-free, and this might explain the better survival and the lower mutation rate of phage DNA in uvrA-recA- bacterial host than in the single $u v r A^{-}$mutant (Fig. 1).

In rec $A^{-} E$. coli strain, a 16-fold increase of $\mathrm{G}: \mathrm{C} \rightarrow$ $\mathrm{T}: \mathrm{A}$ (detected as $\mathrm{G} \rightarrow \mathrm{T}$ in the spectrum, Fig. 4) mutations in comparison to spontaneous mutation frequency was also observed. Comparing the present result with our previous studies performed with ssDNA [17], we observed that this increase was particularly large when the treated DNA was single-stranded (a 73-fold increase), and was not repaired by the NER system, suggesting that the G:C $\rightarrow \mathrm{T}:$ A mutation locus is specifically susceptible to HNE attack. These mutations might arise by a similar mechanism as $\mathrm{G}: \mathrm{C} \rightarrow \mathrm{A}: \mathrm{T}$ transitions $(\mathrm{C} \rightarrow \mathrm{T}$ in the spectrum, Figs. 5, 6). Exocyclic ring of HNE-dG adduct opens easily in dsDNA, which creates linear adducts, that subsequently form internal hemiacetals [40]. The contribution of replicative DNA polymerase as well as pol IV and/or Pol II to bypassing such lesions is highly probable.

$\mathrm{G} \rightarrow \mathrm{T}$ hotspot in the spectrum occurs in recA-deficient, but not in wild-type bacteria, or in uvrA and $\operatorname{rec} A$ deficient strains. We hypothesize that modified $G$ triggers DNA recombination, and when recombination is blocked, induces $\mathrm{G}: \mathrm{C} \rightarrow \mathrm{T}: \mathrm{A}$ transversions. This is supported by the fact that in the uvr $A$ deficient strain $48 \%$ of all mutations are recombination events (Table 2). It is worth to note that when 
HNE treated dsDNA is grown in E. coli recA- strain, the hotspot sequence for $\mathrm{G} \rightarrow \mathrm{T}$ mutation in the spectrum, is $5^{\prime}-G^{*}$ CTGGCGT-3' (see Fig. 4). This is very similar to chi $(\chi)$, a hotspot recombination sequence in E. coli: 5'-GCTGGTGG-3', differing from it in only two nucleotides [41]. It is worth to recall that $\mathrm{G} \rightarrow \mathrm{T}$ transversions are frequent mutations at codon 249 $\left(\mathrm{AGG}^{*}\right.$ ) of the TP53 gene in human cells [42].

In summary, in this work we established the following: (i) Simultaneous deficiency of uvrA and recA in bacterial host diminishes forward mutations in the lac $Z \alpha$ gene, and increases survival of HNE-treated dsDNA M13mp18 phages in comparison to phages propagated in a single $u v r A$ mutant. (ii) By analysis of mutation spectra, we confirmed that HNE-DNA adducts are removed by recA-mediated recombination and $u v r A$-dependent NER repair. (iii) The most frequent type of mutations in HNE-treated DNA of phages grown in wild-type bacteria were G:C $\rightarrow$ A:T transitions, whereas in DNA of phages grown in recAdefective bacteria, yields of $\mathrm{G}: \mathrm{C} \rightarrow \mathrm{T}: \mathrm{A}$ mutations greatly increased, and were located in hotspots. (iv) These hotspots differed for dsDNA and ssDNA. In HNE treated dsDNA they occurred in AGC codon, while in ssDNA, in codon CGT, situated two codons downstream (Fig.4). Both loci are situated in the region which is deleted during recombinational repair. (v) HNE-treated DNA is not repaired by dam-directed mismatch repair system of E. coli. Survival and mutagenesis of phages DNA in transformants after treatment of DNA with various concentrations of HNE were nearly the same whether that DNA replicated in E. coli wild-type, mutL or mutL recA mutants. Surprisingly, when damaged phage was grown in the double $u v r A^{-} r e c A^{-}$mutant strain of $E$. coli as a host, $\mathrm{G}: \mathrm{C} \rightarrow \mathrm{A}: \mathrm{T}$ transitions prevailed. This may suggest that an important fraction of HNE-induced point mutations is formed in an SOS-independent manner.

It was noted previously that the defect in UvrA protein decreases the induction of the SOS response by mitomycin $C$ in $E$. coli rec $A^{+}$cells [43], most probably by decreasing the formation of ssDNA/RecA protein filaments. On the other hand, overproduction of UvrA protein can ameliorate the ultraviolet sensitivity in E. coli recA- strain [44], which suggests that the UvrA and RecA proteins are competing with each other. However, an exact explanation of how the lack of UvrA and RecA proteins decreases mutations at HNE modified G in DNA and helps in survival of bacteria requires further studies.

\section{Acknowledgments}

This work was supported by the grant of the Polish Ministry of Science and Higher Education
N303 328834.

\section{Abbreviations}

8-oxodG: 8-oxo-deoxyguanosine; CDAA: choline-deficient and L-aminoacid- defined diet; $\mathrm{EH}$ : 2,3-epoxy-4-hydroxynonanal; HNE: trans-4-hydroxy-2-nonenal; IPTG: isopropyl- $\beta$-D-thiogalactopyranoside; LPO: lipid peroxidation; $X$-gal: 5-bromo-4-chloro-3-indolyl- $\beta$-D-galactoside; $\quad$ ONE: 4-oxo-2-nonenal; G6PD: glucose-6-phosphate dehydrogenase.

\section{Conflict of Interest}

The authors have declared that no conflict of interest exists.

\section{References}

1. Marnett LJ. Oxyradicals and DNA damage. Carcinogenesis 2000;21:361-370

2. Chung FL, Zhang L. Deoxyguanosine adducts of tert-4-hydroxy-2-nonenal as markers of endogenous DNA lesions. Methods in enzymology 2002;353:523-536

3. Chung FL, Pan J, Choudhury S, Roy R, Hu W, Tang MS. Formation of trans-4-hydroxy-2-nonenal- and other enal-derived cyclic DNA adducts from omega-3 and omega-6 polyunsaturated fatty acids and their roles in DNA repair and human p53 gene mutation. Mutation research 2003;531:25-36

4. Poli G, Schaur RJ, Siems WG, Leonarduzzi G. 4-hydroxynonenal: a membrane lipid oxidation product of medicinal interest. Medicinal research reviews 2008;28:569-631

5. Williams GM, Caldwell J, Armstrong D, Bartsch H, Bevan R, Browne RW, Chipman JK, Iatropoulos MJ, Jeffrey AM, Lunec J, Nair J, Page DL, Reeves BC, Richardson A, Silverstein B, Williams DF. Multicenter study to assess potential hazards from exposure to lipid peroxidation products in soya bean oil from Trilucent breast implants. Regul Toxicol Pharmacol 2009;53:107-120

6. Linnik MD, Zobrist RH, Hatfield MD. Evidence supporting a role for programmed cell death in focal cerebral ischemia in rats. Stroke, a journal of cerebral circulation 1993; 24:2002-2008.

7. Boortz-Marx RL, Clark HB, Taylor S, Wesa KM, Anderson DC. Sneddon's syndrome with granulomatous leptomeningeal infiltration. Stroke, a journal of cerebral circulation 1995;26:492-495

8. Kruman I, Bruce-Keller AJ, Bredesen D, Waeg G, Mattson MP. Evidence that 4-hydroxynonenal mediates oxidative stress-induced neuronal apoptosis. J Neurosci 1997; 17:5089-5100

9. Lovell MA, Ehmann WD, Mattson MP, Markesbery WR. Elevated 4-hydroxynonenal in ventricular fluid in Alzheimer's disease. Neurobiology of aging 1997;18:457-461

10. Portera-Cailliau C, Hedreen JC, Price DL, Koliatsos VE. Evidence for apoptotic cell death in Huntington disease and excitotoxic animal models. J Neurosci 1995;15:3775-3787

11. Gallagher EP, Gardner JL, Barber DS. Several glutathione S-transferase isozymes that protect against oxidative injury are expressed in human liver mitochondria. Biochemical pharmacology 2006;71:1619-1628

12. Nakae D. Endogenous liver carcinogenesis in the rat. Pathology international 1999;49:1028-1042

13. Floyd RA, Kotake Y, Hensley K, Nakae D, Konishi Y. Reactive oxygen species in choline deficiency induced carcinogenesis 
and nitrone inhibition. Molecular and cellular biochemistry 2002;234-235:195-203

14. Kawai Y, Kato Y, Nakae D, Kusuoka O, Konishi Y, Uchida K, Osawa T. Immunohistochemical detection of a substituted $1, \mathrm{~N}(2)$-ethenodeoxyguanosine adduct by omega- 6 polyunsaturated fatty acid hydroperoxides in the liver of rats fed a choline-deficient, L-amino acid-defined diet. Carcinogenesis 2002;23:485-489

15. Felix K, Rockwood LD, Pretsch W, Nair J, Bartsch H, Bornkamm GW, Janz S. Moderate G6PD deficiency increases mutation rates in the brain of mice. Free radical biology \& medicine 2002;32:663-673

16. Feng $\mathrm{Z}, \mathrm{Hu} \mathrm{W}$, Amin $\mathrm{S}$, Tang MS. Mutational spectrum and genotoxicity of the major lipid peroxidation product, trans-4-hydroxy-2-nonenal, induced DNA adducts in nucleotide excision repair-proficient and -deficient human cells. Biochemistry 2003;42:7848-7854

17. Kowalczyk P, Ciesla JM, Komisarski M, Kusmierek JT, Tudek B. Long-chain adducts of trans-4-hydroxy-2-nonenal to DNA bases cause recombination, base substitutions and frameshift mutations in M13 phage. Mutation research 2004;550:33-48

18. Nair J. Lipid peroxidation-induced etheno-DNA adducts in humans. IARC scientific publications:55-61; 1999.

19. Huang H, Wang H, Qi N, Lloyd RS, Rizzo CJ, Stone MP. The stereochemistry of trans-4-hydroxynonenal-derived exocyclic 1,N2-2'-deoxyguanosine adducts modulates formation of interstrand cross-links in the 5'-CpG-3' sequence. Biochemistry 2008;47:11457-11472

20. Benamira M, Marnett LJ. The lipid peroxidation product 4-hydroxynonenal is a potent inducer of the SOS response. Mutation research 1992;293:1-10

21. Cajelli E, Ferraris A, Brambilla G. Mutagenicity of 4-hydroxynonenal in V79 Chinese hamster cells. Mutation research 1987;190:169-171

22. Brambilla G, Sciaba L, Faggin P, Maura A, Marinari UM, Ferro M, Esterbauer H. Cytotoxicity, DNA fragmentation and sister-chromatid exchange in Chinese hamster ovary cells exposed to the lipid peroxidation product 4-hydroxynonenal and homologous aldehydes. Mutation research 1986;171:169-176

23. Hu W, Feng Z, Eveleigh J, Iyer G, Pan J, Amin S, Chung FL, Tang MS. The major lipid peroxidation product, trans-4-hydroxy-2-nonenal, preferentially forms DNA adducts at codon 249 of human p53 gene, a unique mutational hotspot in hepatocellular carcinoma. Carcinogenesis 2002;23:1781-1789

24. Chandra A, Srivastava SK. A synthesis of 4-hydroxy-2-trans-nonenal and 4-(3H) 4-hydroxy-2-trans-nonenal. Lipids 1997;32:779-782

25. Tudek B, Boiteux S, Laval J. Biological properties of imidazole ring-opened N7-methylguanine in M13mp18 phage DNA. Nucleic acids research 1992;20:3079-3084

26. Miller JH. Experiments in Molecular Genetics. NY: Cold Spring Harbor Laboratory, 1972.

27. Messing J. New M13 vectors for cloning. Methods in enzymology 1983;101:20-78

28. Sambrook JF, Maniatis T. Molecular Cloning: A Laboratory Manual. Cold Spring Harbor: Cold Spring Harbor Laboratory Pres, 1989.

29. Messing J. In vitro DNA synthesis as a tool to analyze and alter genes. Basic life sciences 1983;25:9-15

30. Bartsch H, Nair J. Accumulation of lipid peroxidation-derived DNA lesions: potential lead markers for chemoprevention of inflammation-driven malignancies. Mutation research 2005;591:34-44

31. Choudhury S, Pan J, Amin S, Chung FL, Roy R. Repair kinetics of trans-4-hydroxynonenal-induced cyclic 1,N2-propanodeoxyguanine DNA adducts by human cell nuclear extracts. Biochemistry 2004;43:7514-7521
32. Gros L, Ishchenko AA, Saparbaev M. Enzymology of repair of etheno-adducts. Mutation research 2003;531:219-229

33. Delaney JC, Smeester L, Wong C, Frick LE, Taghizadeh K, Wishnok JS, Drennan CL, Samson LD, Essigmann JM. AlkB reverses etheno DNA lesions caused by lipid oxidation in vitro and in vivo. Nature structural \& molecular biology 2005;12:855-860

34. Kurowski MA, Bhagwat AS, Papaj G, Bujnicki JM. Phylogenomic identification of five new human homologs of the DNA repair enzyme AlkB. BMC genomics 2003;4:48

35. Janion C. Inducible SOS response system of DNA repair and mutagenesis in Escherichia coli. International journal of biological sciences 2008;4:338-344

36. Budzowska M, Kanaar R. Mechanisms of dealing with DNA damage-induced replication problems. Cell biochemistry and biophysics 2009;53:17-31

37. Higashitani N, Higashitani A, Horiuchi K. SOS induction in Escherichia coli by single-stranded DNA of mutant filamentous phage: monitoring by cleavage of LexA repressor. Journal of bacteriology 1995;177:3610-3612

38. Minko IG, Kozekov ID, Harris TM, Rizzo CJ, Lloyd RS, Stone MP. Chemistry and biology of DNA containing 1,N(2)-deoxyguanosine adducts of the alpha,beta-unsaturated aldehydes acrolein, crotonaldehyde, and 4-hydroxynonenal. Chemical research in toxicology 2009;22:759-778

39. Fuchs RP, Fujii S. Translesion synthesis in Escherichia coli: lessons from the NarI mutation hot spot. DNA repair 2007;6:1032-1041

40. Huang H, Wang H, Qi N, Kozekova A, Rizzo CJ, Stone MP. Rearrangement of the $(6 \mathrm{~S}, 8 \mathrm{R}, 11 \mathrm{~S})$ and $(6 \mathrm{R}, 8 \mathrm{~S}, 11 \mathrm{R})$ exocyclic 1,N2-deoxyguanosine adducts of trans-4-hydroxynonenal to N2-deoxyguanosine cyclic hemiacetal adducts when placed complementary to cytosine in duplex DNA. Journal of the American Chemical Society 2008;130:10898-10906

41. Dixon DA, Kowalczykowski SC. Homologous pairing in vitro stimulated by the recombination hotspot, Chi. Cell 1991;66:361-371

42. Xing D, Sun L, Cukier RI, Bu Y. Theoretical prediction of the p53 gene mutagenic mechanism induced by trans-4-hydroxy-2-nonenal. The journal of physical chemistry 2007;111:5362-5371

43. Yamamoto K, Higashikawa T, Ohta K, Oda Y. A loss of uvrA function decreases the induction of the SOS functions recA and umuC by mitomycin $\mathrm{C}$ in Escherichia coli. Mutation research 1985;149:297-302

44. Kiyosawa K, Tanaka M, Matsunaga T, Nikaido O, Yamamoto K. Amplified UvrA protein can ameliorate the ultraviolet sensitivity of an Escherichia coli recA mutant. Mutation research 2001;487:149-156

45. Fijalkowska IJ, Schaaper RM. Effects of Escherichia coli dnaE antimutator alleles in a proofreading-deficient mutD5 strain. Journal of bacteriology 1995;177:5979-5986 